\title{
Molecular Interactions in Binary Mixture of Polymethylmethacrylate with Acetic Acid
}

\author{
Richa Saxena (Corresponding author) \& S.C. Bhatt \\ Ultrasonic and Dielectric Laboratory, Department of Physics \\ H.N.B. Garhwal University, Srinagar, Garhwal \\ Uttarakhand-246174, India \\ E-mail: saxena.richa23@gmail.com
}

\begin{abstract}
Solution is prepared by mixing Polymethylmethacrylate in solid form with acetic acid, which at different concentration were used to measure density, viscosity \& ultrasonic velocity in the temperature range $30^{\circ} \mathrm{C}-65^{\circ} \mathrm{C}$, using ultrasonic interferometer at $1 \mathrm{MHz}$. Using these measured values of density, viscosity \& sound velocity, different parameters like, adiabatic compressibility, acoustic impedance and relaxation time have been measured for solution of polymethylmethacrylate with acetic acid under different conditions of temperature and concentration. Variations of above parameters with respect to temperature and concentration have been discussed in terms of molecular interactions.
\end{abstract}

Keywords: Adiabatic compressibility, Acoustic impedance and relaxation time

\section{Introduction}

Polymers are today one of the most important products which surrounds us in every walk of life. Current applications extend from adhesives, coating, foams and packaging materials to textile and industrial fibers, composites, electronic devices, biomedical devices, optical devices and precursors for many newly developed high-tech ceramics. PMMA is used in Lenses, light covers, glazing, light pipes, meter covers, bathroom fittings, outdoor signs, skylights, baths, and toys. The ultrasonic study of liquid mixtures has been gaining importance in assessing the nature of molecular interaction (Arumugam V, 1998, p. 857). During the last few decades, ultrasonic study of liquid mixtures has gained importance for knowing the molecular interactions and understanding the physio-chemical behaviour of liquid (Palaniappan L, 2008, p.1906). The study of molecular interactions present in the polymer and solvent on one hand polymer-polymer and on the other hand is important as it throws light on the processes involving polymer production and their uses (Seetharaman V, 2005, p.156). Velocity measurements yield useful information on the behavior of the polymer solutions (Rim Bae, J, 2004 , p. 559). In general, polymeric mixtures are far less miscible than mixtures of small molecules materials. This effect is a result of the fact that the driving force for mixing is usually entropic, not energetic or miscible materials usually form a material not because their interaction with other is more favorable than their self interaction, but because of an increase in entropy and hence free energy associated with increasing the amount of volume available to each component. This increase in entropy scales with the number of particles (or moles) being mixed. Since polymeric molecules are much larger and generally have much higher specific volumes than small molecules, the numbers of molecules involved in polymer mixtures are far less than number in a small molecules mixture of equal volume. The energetic of mixing, on other hand are comparable on a per volume basis for polymeric and small molecule mixtures.

The studies on ultrasonic parameters have become an emerging field in recent years. The objective of ultrasonic studies is to identify the molecular interaction between solute and solvent and to bring about the structural changes associated with them in terms of acoustic properties like sound velocity, adiabatic compressibility and acoustic impedance etc. Relative variation in the sound velocity in polymethyl methacrylate at intermediate low temperatures has been studied by R. Nava and R. Oentrich (Nava R, 1994, p.337). K. Sudhakar and R.P. Singh (Sudhakar K, 1987, p. 560) have studied the ultrasonic investigation of interpenetrating networks of polymethylmethacrylate and polyurethene. Mechanical and thermal properties of polymethyl methacrylate B.N. Nanotube composites have studied by C.Y. Zhi, et al. (Zhi C Y, 2008, p.1). Kazuhiro kamiguchi et al. ( Kamiguchi, Kazuhiro, 2009, p. 231) has studied the structural characterization of inhomogeneous PMMA gels by time dependent diffusion NMR spectroscopy. The purpose of the present study is to clarify the factors 
contributing to the compressibility in PMMA-acetic acid system over wide range of temperature and concentration, which will be helpful to enhance the knowledge of this PMMA- acetic acid solution as they have for other system.

\section{Experimental Details}

In the present investigation, of polymethylmethacrylate (of molecular weight $\approx 15,000$ in solid form) with acetic acid is used. The solutions were prepared by adding known weight of polymethylmethacrylate to fixed volume of acetic acid and stirring under reflex, until a clear solution was obtained. Different acoustic parameters like adiabatic compressibility, acoustic impedance and relaxation time were calculated at different concentration $0.8 \%, 0.6 \%, 0.5 \%, 0.4 \%$, and $0.3 \%$ (w/v) at different temperatures $30^{\circ} \mathrm{C}, 35^{\circ} \mathrm{C}, 40^{\circ} \mathrm{C}, 45^{\circ} \mathrm{C}, 50^{\circ} \mathrm{C}, 55^{\circ} \mathrm{C}, 60^{\circ} \mathrm{C}$, $65^{\circ} \mathrm{C}$ at $1 \mathrm{MHz}$ frequency by using variable path ultrasonic interferometer (Mittal Enterprises) has reproducibility of $\pm 0.4 \mathrm{~m} / \mathrm{s}$ at $25^{\circ} \mathrm{C}$. The temperature of the solution has been kept constant by circulating water from the thermostatically controlled $\left( \pm 0.1^{\circ} \mathrm{C}\right)$ water bath. In this technique, the sample is kept in a cell, which consists of a double walled metallic jacket having inlet and outlet for circulating thermostatic fluid. A quartz crystal is fixed at the bottom of the cell, which when excited by RF source produces longitudinal ultrasonic waves of particular frequency which propagates in the medium. These waves are reflected at the metallic reflector, attached to a sensitive micrometer which can be moved up and down. The incident and reflected waves form standing wave pattern. By moving the micrometer in the sample, maxima and minima are formed which can be observed in the micrometer of interferometer. These maxima are separated by half integral multiple of the wavelength of the ultrasonic wave. The densities at different temperatures were measured using $10 \mathrm{ml}$ specific gravity bottle and single pan macro balance. The uncertainty in density measurements was found to be $0.5 \mathrm{~kg} / \mathrm{m}^{3}$. The viscosity of the mixtures was determined by using Ostwald viscometer which was kept inside a double-wall-jacket in which water from thermostat water bath was circulated. The inner cylinder of this double-wall-glass jacket was filled with water of desired temperature so as to establish and maintain the thermal equilibrium. The accuracy in the viscosity measurements is within $\pm 0.5 \%$. These parameters are calculated by using standard relations (Bhatt $\mathrm{S} C$, 2000, p. 275; Bhatt S C, 2000, p. 293; Marcue Y, 1977).

$\begin{array}{ll}\text { Ultrasonic velocity } & v=f \lambda \\ \text { Adiabatic compressibility } & \beta=1 / v^{2} \rho \\ \text { Acoustic impedance } & \mathrm{Z}=\rho v \\ \text { Relaxation time } & \tau=4 \eta / 3 \rho v^{2}\end{array}$

Where
$\rho, \quad$ is density of the medium.
$v$, is the ultrasonic velocity in the medium.
$\eta, \quad$ is viscosity of the medium.
$f$, is frequency.
$\lambda, \quad$ is wavelength

\section{Results \& Discussion}

In a dilute solution, the properties of polymer are characterized by the interaction between the solvent and the polymer. In a good solvent, the polymer appears swollen and occupies a large volume. In this scenario, intermolecular forces between the solvent and monomer subunits dominate over intermolecular interactions. When a polymer is added to given solvent, attraction as well as dispersion forces begin acting between its segments, according to their polarity, chemical characteristics and solubility parameters. If the polymer-solvent interactions are higher than the polymer-polymer attraction forces, the chain segment start to absorb solvent molecules, increasing the volume of the polymer matrix and loosening out from their coiled shape.

In the present investigation density, viscosity and ultrasonic velocity are measured at different temperature and concentration of polymethylmethacrylate with acetic acid, which are shown in Table-1, 2, and 3 respectively and the variation with temperature and concentration are shown in Fig. $1 \& 2$, Fig. $3 \& 4$ and Fig.5 \& 6 respectively. By using these values for PMMA of (molecular weight $\approx 15000$ ) adiabatic compressibility, acoustic impedance and relaxation time are calculated using equations (2),(3) \& (4) respectively and the results are presented in Table-4, $5 \& 6$ respectively. The variations of these parameters with temperature and concentration are shown in Fig. 7 to Fig. 12 respectively. 
The variation of density with temperature and concentration is shown in Table-1 and Fig. $1 \& 2$ respectively. It is observed from Table-1 and Fig.1 \& 2, that density decreases with increase in temperature and increases with increase in concentration. Measurements of density and for a range of frequencies may lead to a better understanding of the molecular mechanisms responsible for absorption and velocity such as relaxation (Esquivel-Sirvent R, 1993, p.819). Table-2, presents the change in viscosity with temperature and concentration, the variations are shown in Fig.3 and 4 respectively. Table-2 and Fig. 3 \& 4, reports that viscosity decreases with increasing temperature and it increases with increasing concentration of PMMA in the solution. Similar behaviour has been observed by Surbha and coworkers (Surendra babu N, 2002, p.505). The increasing trend of viscosity with concentration reveals that addition of polymer (PMMA) increases the effective molecular area (Eliel E L, 1985, p. 95). The measurement of viscosity in dilute macromolecular solution has fundamental importance not only in determination of molecular weights, but also in the evaluation of key parameters for the understanding of the conformational characteristics of the polymer solutions. The variations of ultrasonic velocity with temperature and concentration have been shown in Table-3, and Fig. 5 \& 6 , respectively. It is evident from Table-3 and Fig.5 \& 6, that ultrasonic velocity decreases with increase in temperature and it increases with increase in concentration. Present values are compared with available values in literature. These are in good agreement with earlier work's (Varada Rajulu A, 1999, p. 379; Selvakumar M, 2008, p. 712) findings. Velocity studies show that as the polymer concentration increases a more rigid molecular structure is formed perhaps by bonding between the large polymer molecules.

Table-4 and Fig.7 \& 8, shows the variation of adiabatic compressibility with temperature and concentration respectively. It is observed from Table-4 and Fig. $7 \& 8$, that adiabatic compressibility increases with increasing temperature and decreases with increasing concentration. This can be explained in terms of the electrostatic effect of polymer on the surrounding solvent molecules. It is primarily the compressibility that changes with structure. This leads to change in ultrasonic velocity. The variation of acoustic impedance with temperature and concentration are shown in Table-5 and Fig.9 \&10. It is seen from Table-5 and Fig.9 \& 10, that acoustic impedance decreases with increase in temperature and it increases with increase in concentration, which can be attributed to the effective solute-solvent interactions (Syal V K, 2005, p. 61). Table-6 shows the change in relaxation time with change in temperature and concentration. The variation of relaxation time with temperature \& concentration are shown in Fig. 11 \& 12 respectively. It is observed from Table- 6 and Fig. 11 \& 12 that relaxation time decreases with increasing temperature also it decreases with increasing concentration. The above behaviour is obvious as per kinetic theory of fluids. The variation of relaxation time is a cumulative effect of the density, viscosity and ultrasonic velocity.

\section{Conclusions}

It also shows the nature of polymer in solvent at different concentration and temperature and to study intermolecular interactions. Those in turns are useful for production and uses of polymers in pharmaceuticals and industry.

\section{References}

Arumugam, V., Naresh, M.D., Sanjeevi R. (1998). Ultrasonic study of Collagen solutions. J. Solution chemistry, $27,857-864$.

Bhatt, S. C., Semwal, H. K., Lingwal, V., Singh, K., Semwal, B. S. (2000). Acoustical parameters of some molecular liquids. J. Acous. Soc. India, 28, 293-296.

Bhatt, S. C., Semwal, H. K., Lingwal, V., Singh, K., Semwal, B. S. (2000). Relaxation time and ultrasonic attenuation in some binary and ternary liquid systems. J. Acous. Soc. India, 28, 275-278.

Eliel, E.L. (1985). Stereochemistry of carbon compounds, $9^{\text {th }}$ ed., New Delhi, Tata McGraw Hill, 95-97.

Esquivel-Sirvent, R., Tan, B., Abdelraziq, I., Yunand, S. S., Stump, F. B. (1993). Absorption and velocity of ultrasound in binary solutions of polyethylene glycol and water. J. Acous. Soc. Am., 93, 819-820.

Kamiguchi, Kazuhiro, Kuroki, Shigeki., Satoh, M., Ando, Isao. (2009). Structural characterization of inhomogenous polymethylmethacrylate gels by time dependent diffusion NMR spectroscopy. Macromolecules, 42, 231-235.

Marcue Y. (1977). Introduction to liquid State chemistry, (New York, Wiley Int.).

Nava, R., Oentrich R. (1994). Relative variation in the sound velocity in polymethyl methacrylate at intermediate low temperature. J. Alloys and compounds, 211/212, 337-339. 
Palaniappan, L., Thiyagarajan, R. (2008). Effect of aniline in methanol + benzene mixture- An ultrasonic study. Ind. J. Chem., 47B, 1906-1909.

Rim Bae, J. (2004). Ultrasonic velocity and absorption measurements in an aqueous solution of poly(sodium 4styrenesulfonate). Macromolecular Research, 12, 559-563.

Seetharaman, V., Kalyanasundaram, S., Gopalan A. (2005). Quantitatively study of interaction of vinyl polymers by ultrasonic method. J. of molecular liquids, 121, 156-159.

Selvakumar M., Krishna Bhat D. (2008). Molecular interactions of Polymethyl methacrylate and Polyethyleneglycol solutions in tetrahydrofuran. Indian Journal of Pure and Applied Physics, 46, 712-718.

Sudhakar, K., Singh, R. P. (1987). Ultrasonic investigation of interpenetrating networks of Poly(methyl methacrylate) and polyurethane. Rheologica Acta, 26, 560-565.

Surendra babu, N., Subha, M. C. S. (2002). Effect of polymer and temperature on the critical micellar concentration of aqueous sodium dodecylsulfate. J. Indian chem. Soc., 79, 505-508.

Syal, V. K., Chauhan, A., Chauhan, S. (2005). Ultrasonic velocity, viscosity and density studies of polyethylene glycols in acetonitrile and water mixtures at $25^{\circ} \mathrm{C}$. J. pure Appl. Ultrason, 27, 61-69.

Varada Rajulu, A., Lakshminarayana Reddy, R. (1999). Ultrasonic, refractometric and viscosity studies of polyethylene oxide/polymethylmethacrylate and polyethylene oxide/polystyrene blends in solution. J. Acous Soc. India, 27, 379-382.

Zhi, C. Y., Bando Yoshio, L., Wang W., C.,Tang, Chengchun. (2008). Mechanical and thermal properties of PMMA - BN nanotube composites. J. Nanomaterials, Article ID 642036, 1-5.

Table 1. Density $\left(\mathrm{x}^{3} 0^{3} \mathrm{kgm}^{-3}\right)$ at different temperature and concentration at $1 \mathrm{MHz}$ for PMMA

\begin{tabular}{ccccccccc}
\hline $\begin{array}{c}\text { Temperature } \longrightarrow \\
\begin{array}{c}\text { Concentration } \\
(\mathrm{w} / \mathrm{v})\end{array}\end{array}$ & $30^{\circ} \mathrm{C}$ & $35^{\circ} \mathrm{C}$ & $40^{\circ} \mathrm{C}$ & $45^{0} \mathrm{C}$ & $50^{\circ} \mathrm{C}$ & $55^{\circ} \mathrm{C}$ & $60^{\circ} \mathrm{C}$ & $65^{0} \mathrm{C}$ \\
\hline $0.8 \%$ & 1.05 & 1.04 & 1.03 & 1.01 & .994 & 0.10 & 0.96 & 0.94 \\
$0.6 \%$ & 1.04 & 1.04 & 1.03 & 1.01 & 1.00 & 0.99 & 0.98 & 0.96 \\
$0.5 \%$ & 1.08 & 1.06 & 1.05 & 1.04 & 1.02 & 1.01 & 0.99 & 0.98 \\
$0.4 \%$ & 1.04 & 1.03 & 1.02 & 1.01 & 1.00 & 0.99 & 0.98 & 0.97 \\
$0.3 \%$ & 0.91 & 0.91 & 0.90 & 0.89 & 0.88 & 0.87 & 0.85 & 0.83 \\
\hline
\end{tabular}

Table 2. Viscosity (Pas) at different temperature and concentration at 1MHz for PMMA

\begin{tabular}{ccccccccc}
\hline $\begin{array}{c}\text { Temperature } \\
\text { Concentration(w/v) }\end{array}$ & $30^{0} \mathrm{C}$ & $35^{0} \mathrm{C}$ & $40^{0} \mathrm{C}$ & $45^{0} \mathrm{C}$ & $50^{0} \mathrm{C}$ & $55^{0} \mathrm{C}$ & $60^{0} \mathrm{C}$ & $65^{0} \mathrm{C}$ \\
\hline $0.8 \%$ & .0126 & .0105 & .0089 & .0074 & .0069 & .0063 & .0059 & .0061 \\
$0.6 \%$ & .0097 & .0087 & .0076 & .0071 & .0069 & .0061 & .0059 & .0053 \\
$0.5 \%$ & .0101 & .0089 & .0080 & .0075 & .007 & .0064 & .0059 & .0058 \\
$0.4 \%$ & .0098 & .0085 & .0076 & .0072 & .0067 & .0062 & .0058 & .007 \\
$0.3 \%$ & .0085 & .0075 & .0069 & .0065 & .0058 & .0056 & .0052 & .0048 \\
\hline
\end{tabular}


Table 3. Ultrasonic velocity $\left(\mathrm{ms}^{-1}\right)$ at different temperature and concentration at $1 \mathrm{MHz}$ for PMMA

\begin{tabular}{ccccccccc}
\hline $\begin{array}{c}\text { Temperature } \\
\text { Concentration(w/v) }\end{array}$ & $30^{\circ} \mathrm{C}$ & $35^{0} \mathrm{C}$ & $40^{\circ} \mathrm{C}$ & $45^{0} \mathrm{C}$ & $50^{0} \mathrm{C}$ & $55^{0} \mathrm{C}$ & $60^{0} \mathrm{C}$ & $65^{0} \mathrm{C}$ \\
\hline $0.8 \%$ & 1232.4 & 1229.5 & 1219.6 & 1213.7 & 1204.8 & 1201.2 & 1199.8 & 1194.6 \\
$0.6 \%$ & 1215.2 & 1215.4 & 1205.4 & 1197.4 & 1192.6 & 1190.1 & 1187.0 & 1182.0 \\
$0.5 \%$ & 1210.7 & 1196.6 & 1195.3 & 1193.5 & 1181.4 & 1176.5 & 1172.7 & 1170.7 \\
$0.4 \%$ & 1197.4 & 1182.1 & 1177.4 & 1172.3 & 1168.5 & 1162.3 & 1161.4 & 1158.0 \\
$0.3 \%$ & 1190.2 & 1182.6 & 1172.3 & 1165.7 & 1163.2 & 1160.4 & 1158.3 & 1154.2 \\
\hline
\end{tabular}

Table 4. Adiabatic compressibility $\left(\times 10^{-10} \mathrm{~kg}^{-1} \mathrm{~ms}^{2}\right)$ at different temperature and concentration at $1 \mathrm{MHz}$ for PMMA

\begin{tabular}{ccccccccc}
\hline $\begin{array}{c}\text { Temperature } \longrightarrow \\
\text { Concentration(w/v) }\end{array}$ & $30^{\circ} \mathrm{C}$ & $35^{\circ} \mathrm{C}$ & $40^{\circ} \mathrm{C}$ & $45^{\circ} \mathrm{C}$ & $50^{\circ} \mathrm{C}$ & $55^{\circ} \mathrm{C}$ & $60^{\circ} \mathrm{C}$ & $65^{\circ} \mathrm{C}$ \\
\hline $0.8 \%$ & 6.27 & 6.38 & 6.56 & 6.71 & 6.93 & 6.96 & 7.27 & 7.44 \\
$0.6 \%$ & 6.41 & 6.52 & 6.70 & 6.89 & 7.01 & 7.13 & 7.27 & 7.47 \\
$0.5 \%$ & 6.33 & 6.59 & 6.68 & 6.78 & 7.00 & 7.16 & 7.34 & 7.47 \\
$0.4 \%$ & 6.71 & 6.98 & 7.08 & 7.20 & 7.32 & 7.48 & 7.59 & 7.72 \\
$0.3 \%$ & 7.72 & 7.89 & 8.11 & 8.29 & 8.44 & 8.61 & 8.81 & 9.07 \\
\hline
\end{tabular}

Table 5. Acoustic impedance $\left(10^{3} \mathrm{kgm}^{2} \mathrm{~s}^{-1}\right)$ at different temperature and concentration at $1 \mathrm{MHz}$ for PMMA Temperature $\longrightarrow 30^{\circ} \mathrm{C} \quad 35^{\circ} \mathrm{C} \quad 40^{\circ} \mathrm{C} \quad 45^{\circ} \mathrm{C} \quad 50^{\circ} \mathrm{C} \quad 5^{\circ} \mathrm{C} \quad 60^{\circ} \mathrm{C} \quad 65^{\circ} \mathrm{C}$ Concentration

\begin{tabular}{|c|c|c|c|c|c|c|c|c|}
\hline $0.8 \%$ & 1294.6 & 1275.7 & 1250.7 & 1227.4 & 1197.8 & 1196.0 & 1146.7 & 1125.2 \\
\hline $0.6 \%$ & 1276.7 & 1261.4 & 1238.8 & 1212.1 & 1196.8 & 1178.4 & 1158.4 & 1132.0 \\
\hline $0.5 \%$ & 1305.3 & 1268.2 & 1252.2 & 1235.5 & 1208.7 & 1187.6 & 1162.4 & 1143.9 \\
\hline $0.4 \%$ & 1243.9 & 1211.9 & 1199.1 & 1185.2 & 1168.7 & 1150.8 & 1135.2 & 1119.1 \\
\hline $0.3 \%$ & 1087.8 & 1071.7 & 1051.6 & 1034.9 & 1018.6 & 1001.0 & 979.6 & 955.1 \\
\hline
\end{tabular}

Table 6. Relaxation time $\left(\times 10^{-12} \mathrm{~s}\right)$ at different temperature and concentration at $1 \mathrm{MHz}$ for PMMA

\begin{tabular}{ccccccccc}
\hline $\begin{array}{c}\text { Temperature } \\
\text { Concentration(w/v) }\end{array}$ & $30^{\circ} \mathrm{C}$ & $35^{0} \mathrm{C}$ & $40^{0} \mathrm{C}$ & $45^{\circ} \mathrm{C}$ & $50^{\circ} \mathrm{C}$ & $55^{\circ} \mathrm{C}$ & $60^{\circ} \mathrm{C}$ & $65^{\circ} \mathrm{C}$ \\
\hline $0.8 \%$ & 8.58 & 8.93 & 7.78 & 6.64 & 6.35 & 5.8 & 5.75 & 6.05 \\
$0.6 \%$ & 8.33 & 7.57 & 6.8 & 6.53 & 6.45 & 5.82 & 5.70 & 5.31 \\
$0.5 \%$ & 8.20 & 7.84 & 7.15 & 6.78 & 6.50 & 6.12 & 5.73 & 5.76 \\
$0.4 \%$ & 8.66 & 7.86 & 7.18 & 6.91 & 6.53 & 6.18 & 5.90 & 5.14 \\
$0.3 \%$ & 8.75 & 7.89 & 7.42 & 7.18 & 6.53 & 6.43 & 6.11 & 5.81 \\
\hline
\end{tabular}




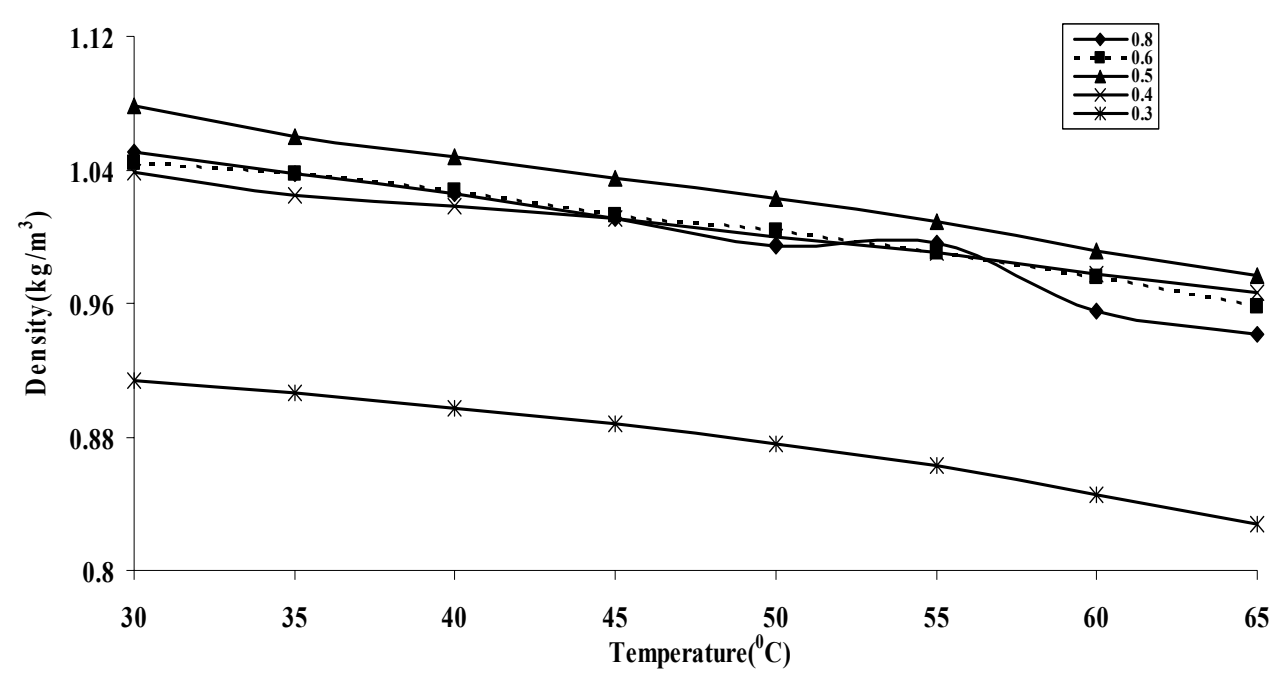

Figure 1. Variation of density with temperature at different concentration of PMMA

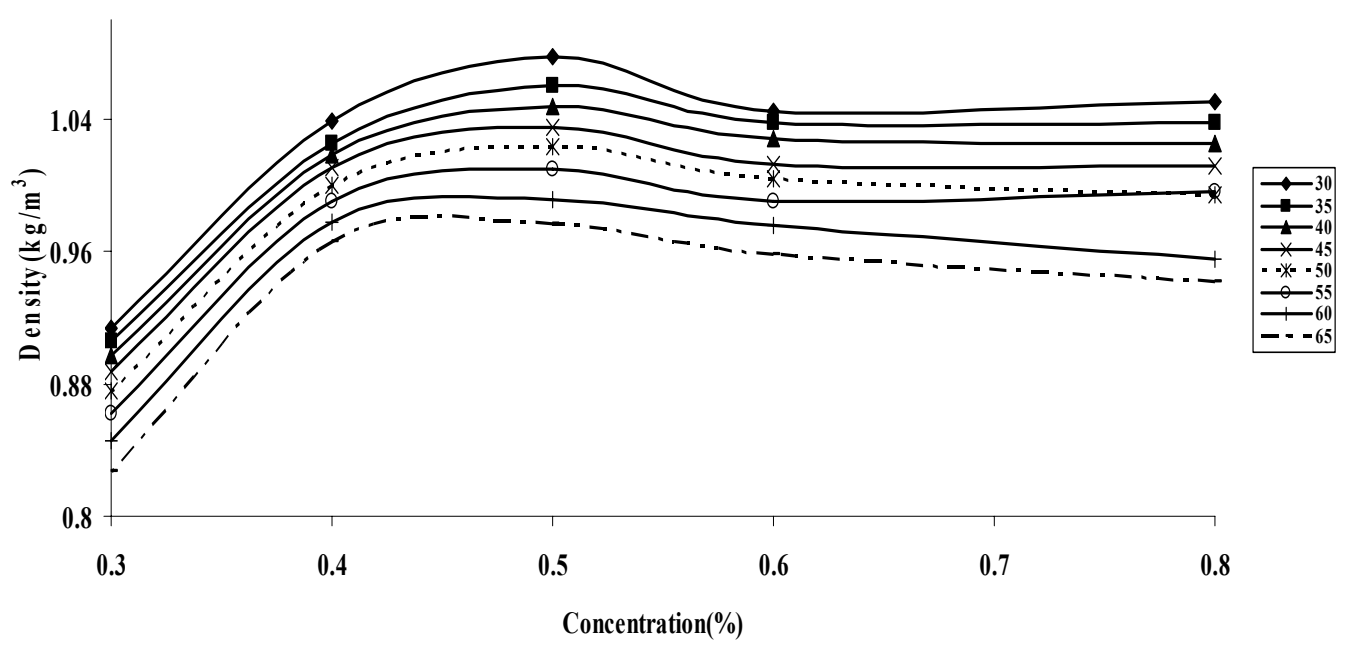

Figure 2. Variation of density with concentration at different temperature of PMMA

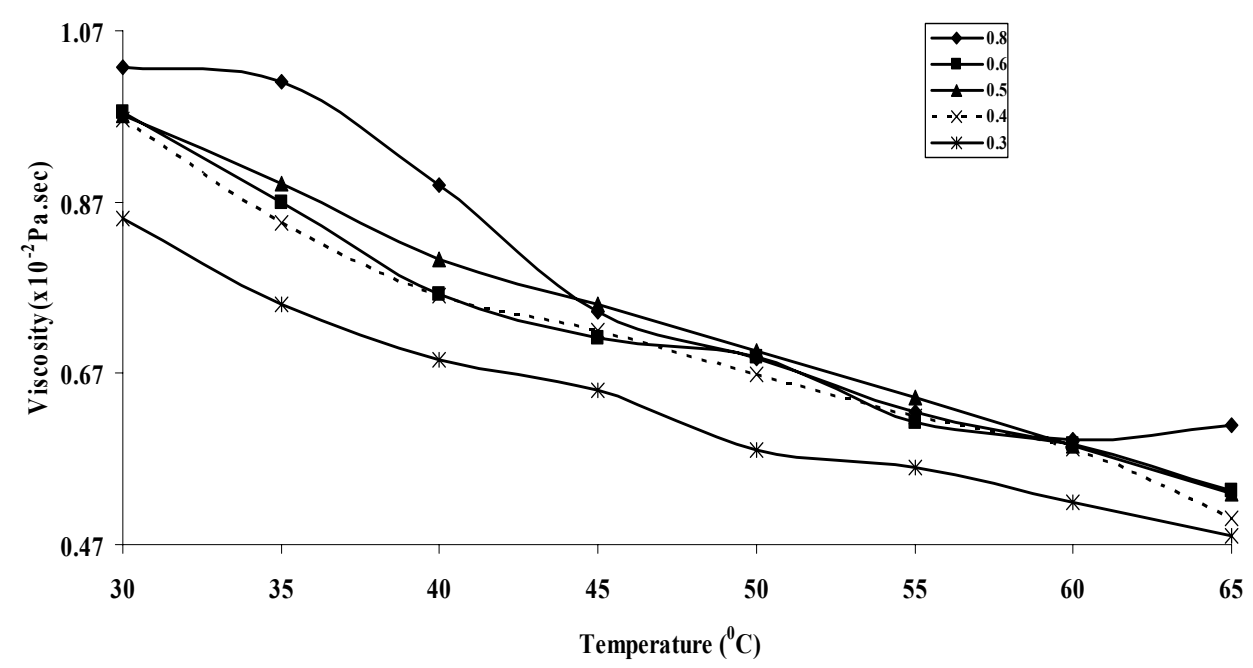

Figure 3. Variation of viscosity with temperature at different concentration of PMMA 


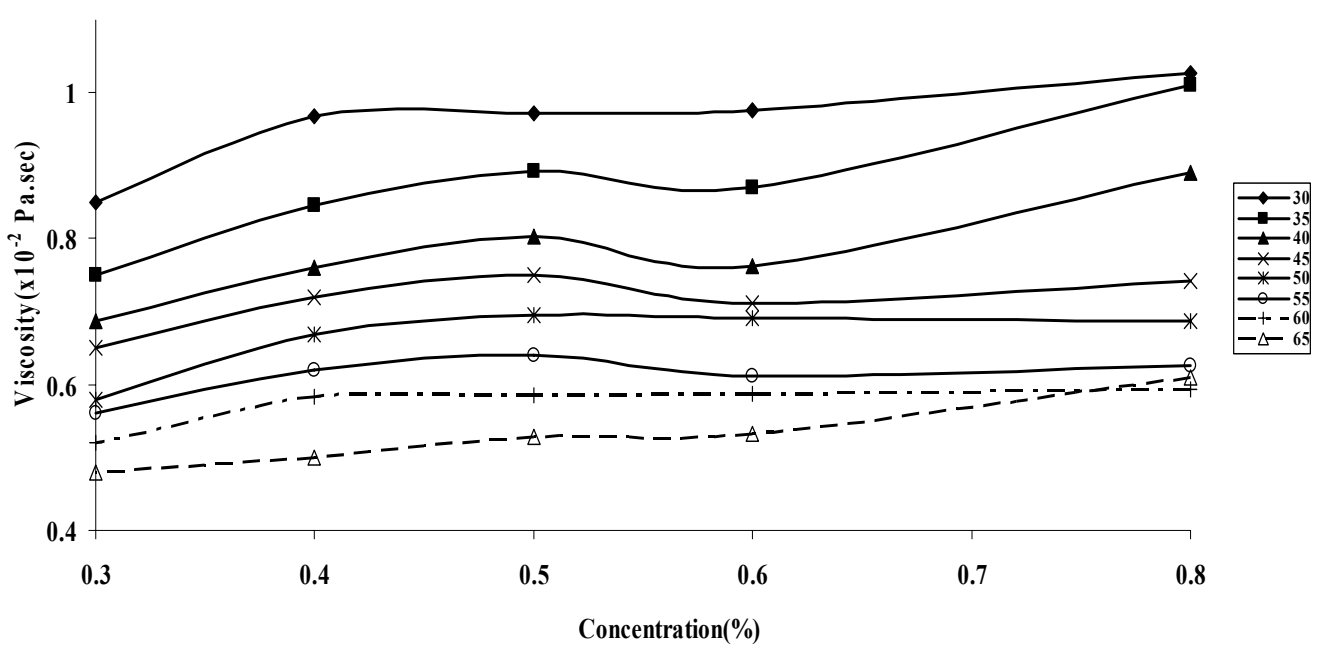

Figure 4. Variation of viscosity with concentration at different temperature of PMMA

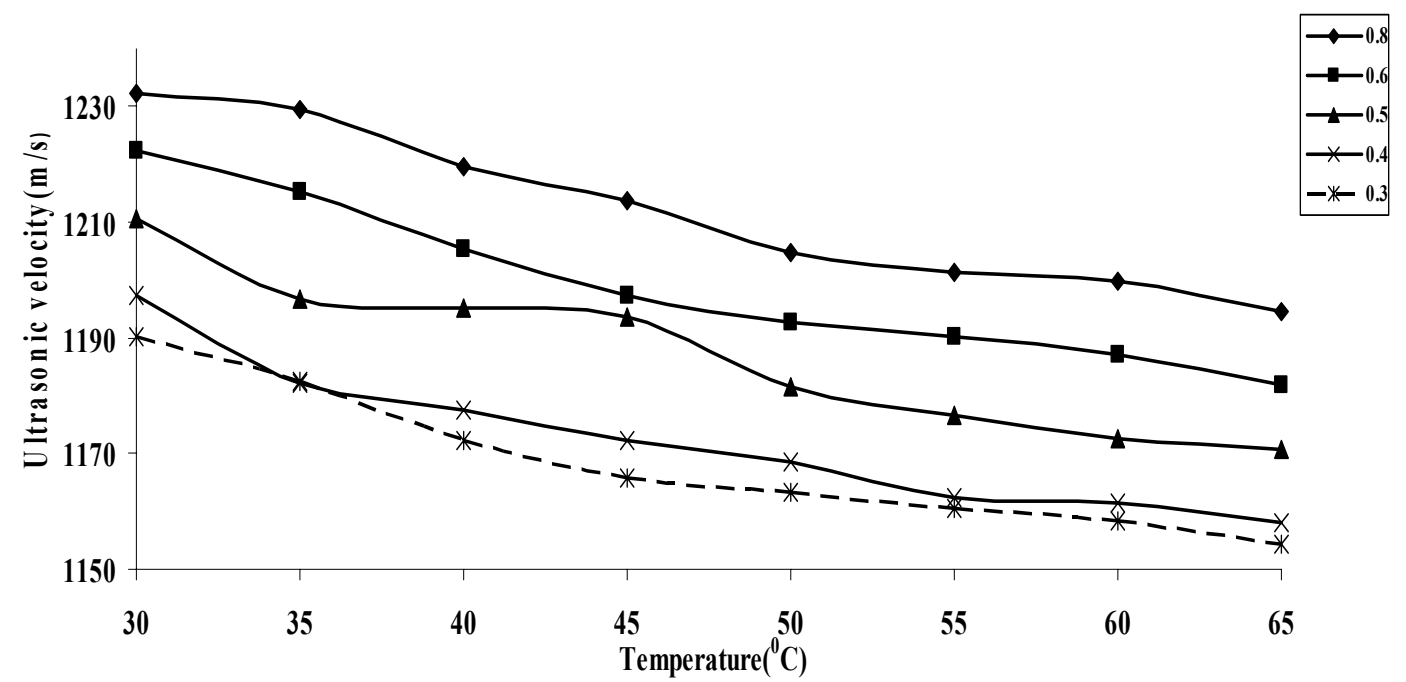

Figure 5. Variation of ultrasonic velocity with temperature at different concentration of PMMA

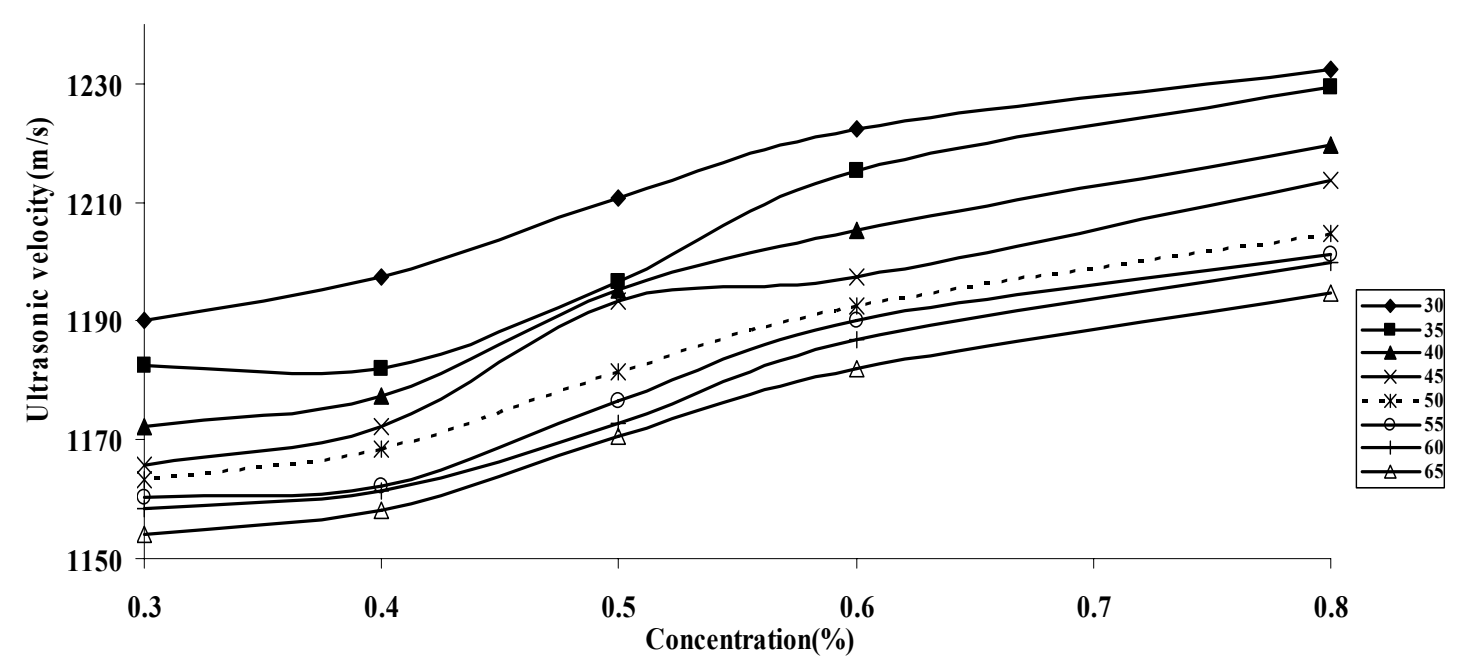

Figure 6. Variation of ultrasonic velocity with concentration at different temperature of PMMA 


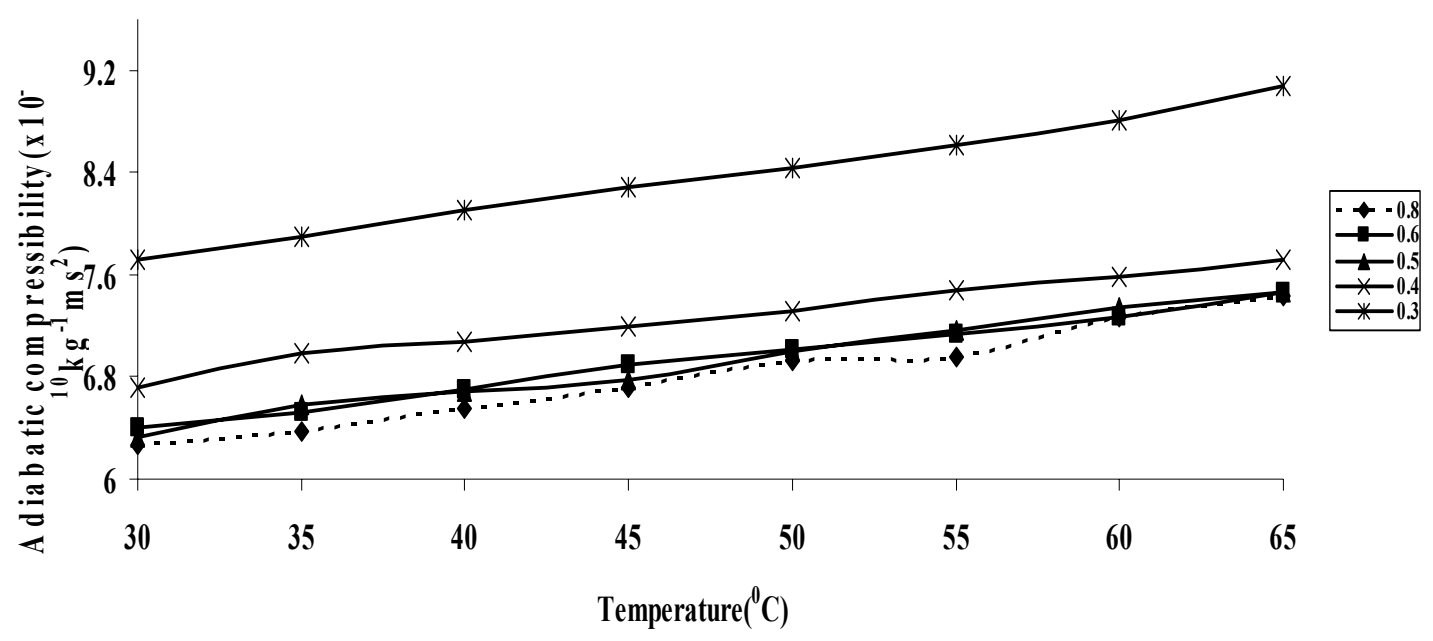

Figure 7. Variation of adiabatic compressibility with temperature at different concentration of PMMA
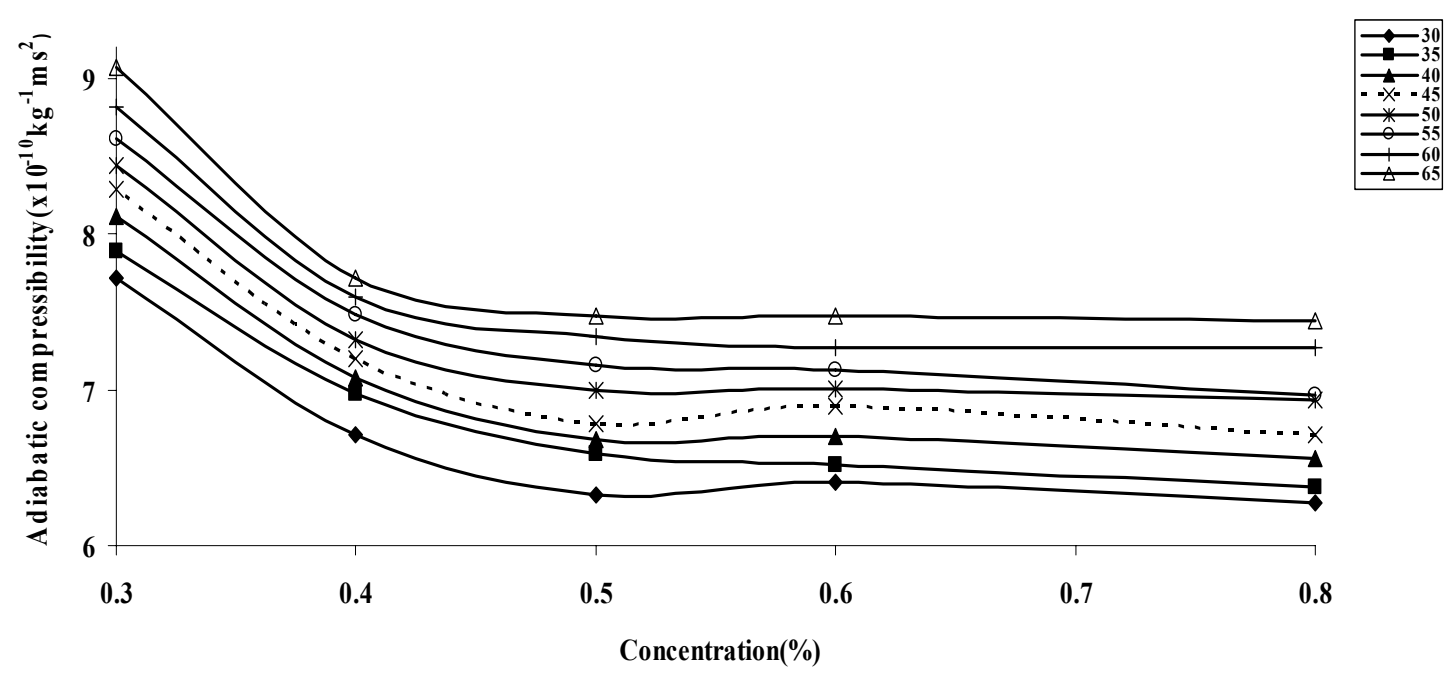

Figure 8. Variation of adiabatic compressibility with concentration at different temperature of PMMA

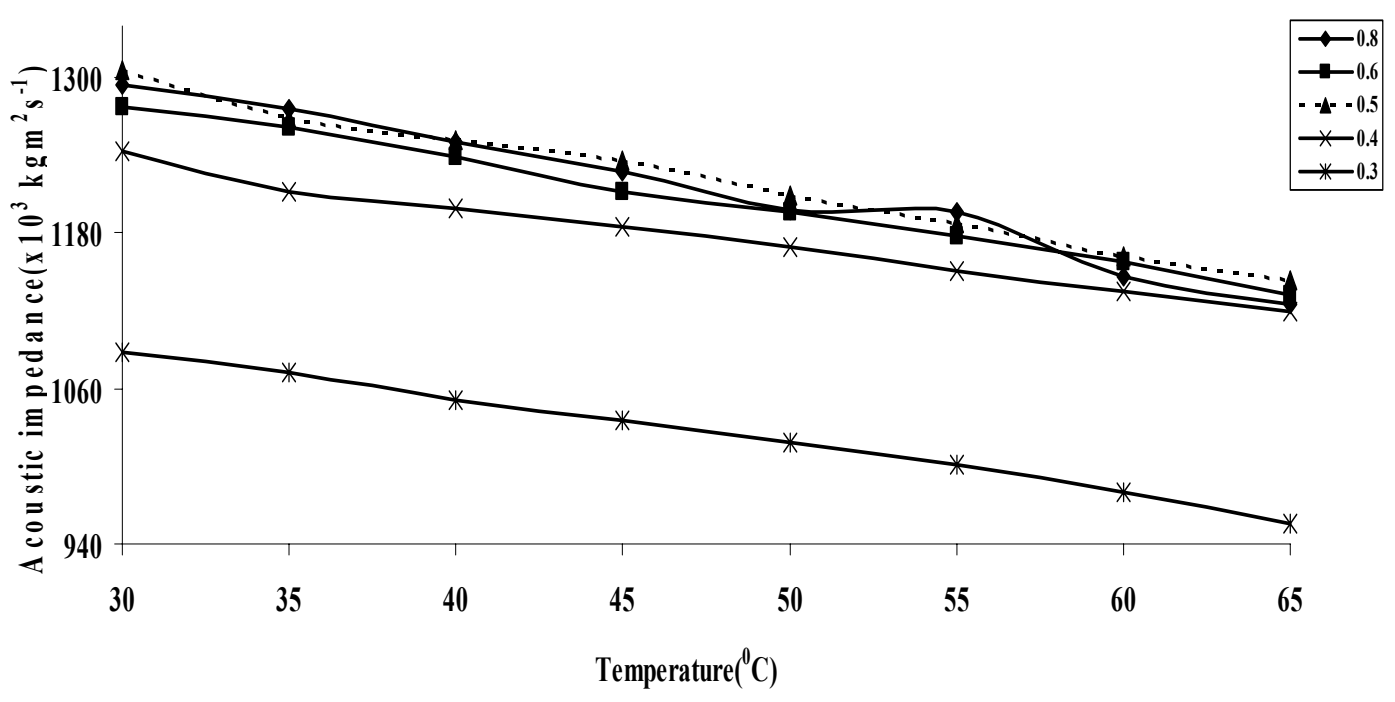

Figure 9. Variation of acoustic impedance with temperature at different concentration of PMMA 


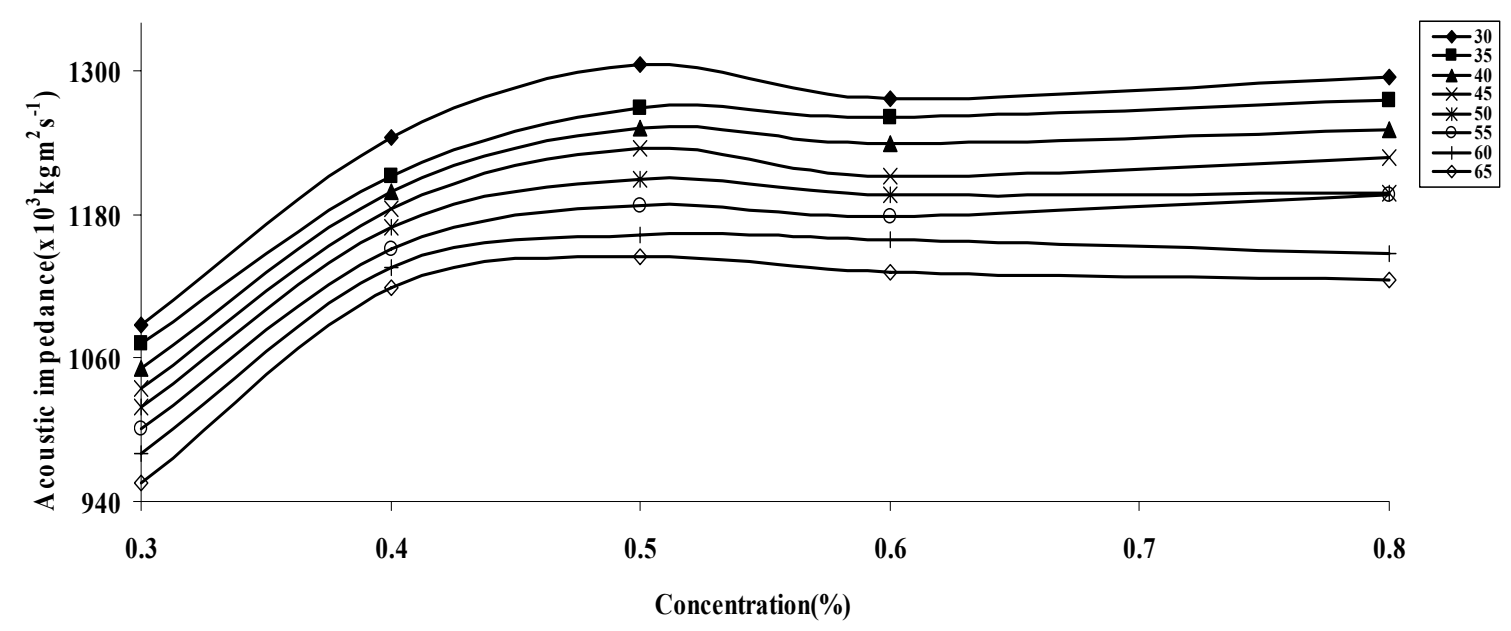

Figure 10. Variation of acoustic impedance with concentration at different temperature of PMMA

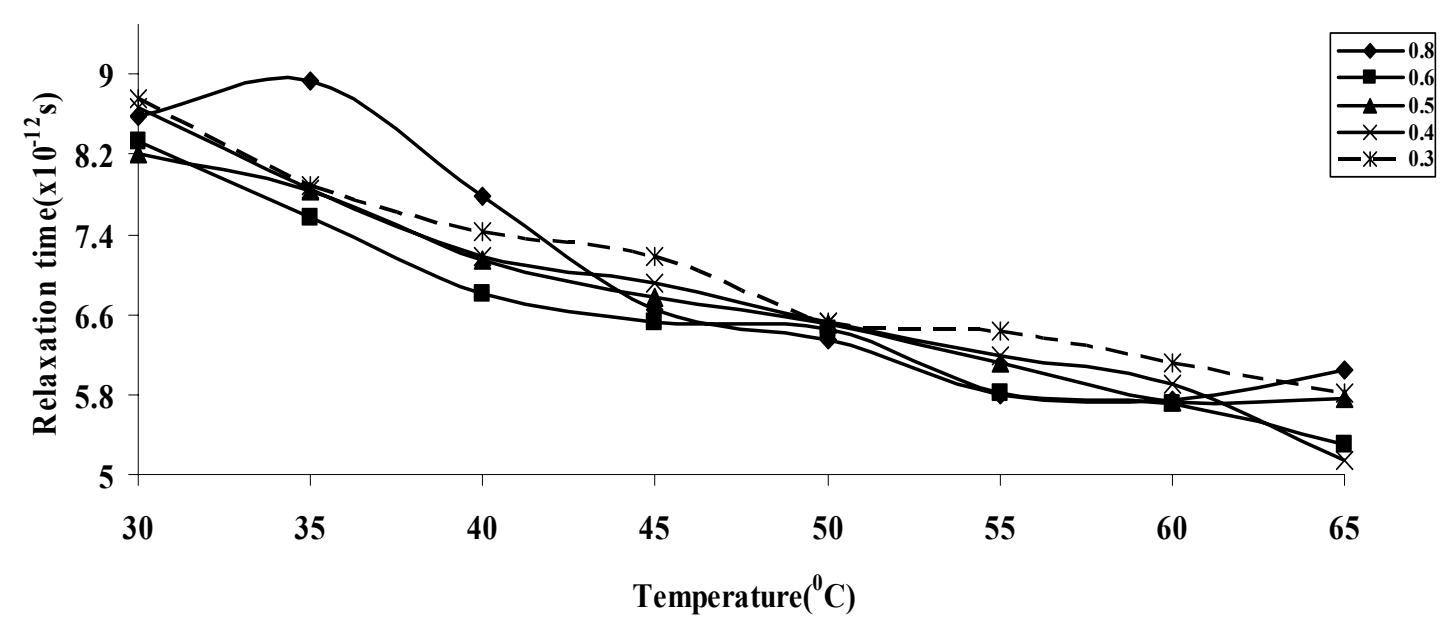

Figure 11. Variation of relaxation time with temperature at different concentration of PMMA

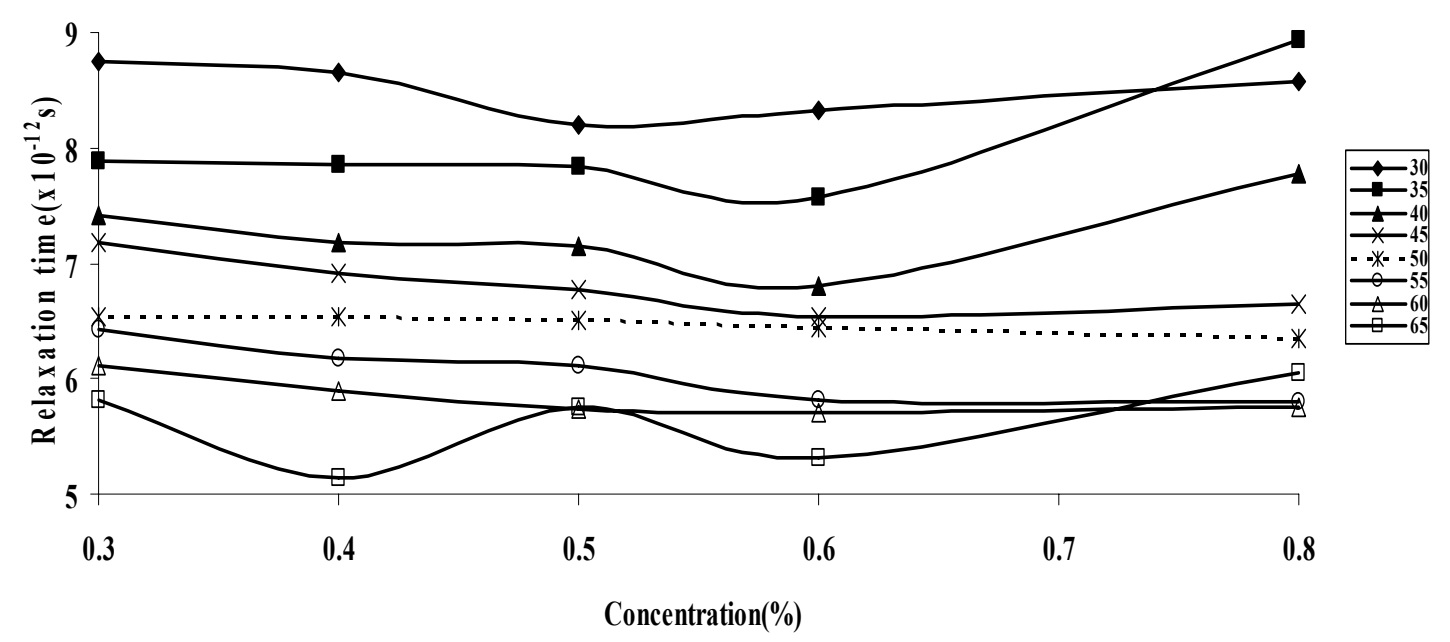

Figure 12. Variation of relaxation time with concentration at different temperature of PMMA 